\title{
Analysis of Dynamic Response on Double-Column Bridge Piers of Mountainous Area based on the Collision of Rolling Stones
}

\author{
Wang Zijian ${ }^{1}$, Zhang Jianing, ${ }^{1, *}$ Hu Jinpeng ${ }^{1}$, Yang Bo ${ }^{1}$, Wu Liming ${ }^{2}$ and Piao Lihua ${ }^{3}$ \\ ${ }^{I}$ School of Architecture and Engineering, Chongqing University of Science and Technology, Chongqing 40041, China \\ ${ }^{2}$ School of Urban Construction Engineering, Chongqing Business Vocational College, Chongqing, 401520, China \\ ${ }^{3}$ Bank of Hope, New York, NY 11354, United States
}

Received 3 February 2020; Accepted 11 April 2020

\begin{abstract}
Anti-rolling stone collision design for mountain bridges is the key link of bridge design in mountainous area. However, the existing research of bridge structures based on collision bears limitations. Only a few studies on the dynamic response of bridge piers based on rolling stone collision are available. Explorations on the problem of the rolling stone colliding bridge piers are limited, and the anti-rolling stone collision design of bridge piers is blind. This study took the Chang $\mathrm{Ba}$ Bridge of Nan Chuan District located at Chongqing of China as a specific research object prototype. A simulation analysis of the dynamic response of double-column bridge piers under rolling stone collision was conducted in this study to improve the anti-rolling stone collision performance of bridge piers and reduce their damage under the rolling stone collision. This analysis utilized display dynamics analysis software ANSYS/LS-DYNA to establish the rolling stonepier collision model and extracted stress time-history and displacement curves of the key part of bridge pier structures. This study compared and analysed the dynamic response of the bridge pier under different initial velocities and different collision positions of the rolling stone.The results demonstrate that the maximum value of stress variation of the bridge pier structure decrease with the reduction of the distance from the collision position to the bottom of the bridge pier when the bridge pier collided by rolling stones with the same initial velocity and different collision positions. This phenomenon indicates that the dynamic response of the bridge pier under the rolling stone collision is affected by the bottom constraint of the bridge pier. The stress of the bridge pier concentrates on the connecting part of the bridge pier and the coupling beam. This phenomenon indicates the vulnerability of the connecting part of the bridge pier and the coupling beam, except for the collided area of the bridge pier. Maximum stresses of the longitudinal reinforcement and the stirrup don't exceed $35 \mathrm{MPa}$. Thus, the longitudinal reinforcement and the stirrup of the bridge pier don't reach yield strength and can still participate in force with the bridge pier concrete. Conclusions obtained in the study can provide theoretical references for the anti-rolling stone collision design of double-column piers in mountainous area.
\end{abstract}

Keywords: Mountain bridge, Double-column bridge piers, Anti-rolling stone collision, ANSYS/LS—DYNA

\section{Introduction}

With the rapid development of transportation infrastructure in mountainous area of western China, several bridges are constructed in mountainous area. However, the terrain of mountainous area in western China contains many river valleys and deep grooves. These bridges are often built on steep slopes, wherein suitable bridge piers must be chosen to avoid excessive use of mountain resources. Under this circumstance, double-column bridge piers have become the most common pier form in mountain bridges. These piers not only protect the limited cultivated land resource in mountainous area of western China but also effectively reduce material consumption and improve construction efficiency. Double-column bridge piers are widely used in mountain bridge construction. However, the rigidity of double-column bridge piers is poor, and double-column bridge piers are easily damaged by the collision of rolling stones. The southwestern part of China is a high earthquake intensity region, wherein earthquake disasters frequently occurred in recent years. Earthquake occurrence aggravates

*E-mail address: zhang793668206@163.com

ISSN: $1791-2377 \bigcirc 2020$ School of Science, IHU. All rights reserved. doi:10.25103/iestr.133.15 the risk of rolling stone disaster and frequently results in accidental collisions of bridge piers due to rolling stones. The destructive force of rolling stone disaster in mountainous area is enormous. The security of various transportation infrastructure and personnel activities in the location would be considerable affected once bridge piers are damaged by the collision of a rolling stone. For example, a large-area collapse occurred in the high rock mass on the right bank of the Minjiang River of China in 2009, and the $8 \#$ bridge pier was instantly broken by the collision of rolling stones. These phenomena resulted in the breakage of beam body of the bridge pier. During this accident, 3 people died, 12 people were injured, and traffic was interrupted, as shown in Fig. 1. A rolling stone disaster due to continuous rainfall occurred at Jijiaoling Tunnel of Xihan Highway in China in 2011. This disaster resulted in the breakage of three beams. In 1983, rolling stones hit the bridge of the road section from Xiangyu Highway to Bashan, which resulted in a huge loss. Thus, anti-rolling stone collision design of mountain bridges is the key link of bridge design in mountainous area.

The formation of rolling stone disasters is attributed to the stability loss of stones under the combined effect of their gravity and internal and external factors. People will generally construct structures, such as blocking walls and 
protective nets, to intercept the movement of a rolling stone or change its trajectory such these stones could not reach the position of bridge piers [1]. However, the formation of rolling stones is affected by many factors, such as local soil characteristics, geological conditions, rainfall, and human activities. The accuracy on the design of anti-rolling stone collision measures is limited by these factors. The rolling stone may possess the following characteristics: regular or irregular shape, big or small size, uncertain quantity, and diverse motion trajectory. Compared with the traditional anti-rolling stone collision measures, to research the dynamic response of the bridge pier under the rolling stone collision, we can view from the perspective of the dynamic characteristics of the bridge pier material, the destruction level of bridge piers caused by the collision of rolling stones can be ameliorated [2], the anti-collision performance of the bridge pier can be improved, and the accuracy of the antirolling collision design of the bridge pier can be increased. Therefore, the dynamic response research on bridge piers based on the rolling stone collision is crucial to improve the anti-rolling stone collision performance and its design accuracy of bridge piers.

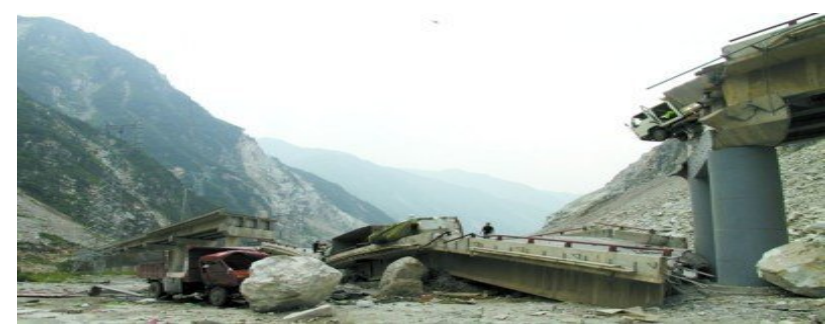

Fig. 1. Collapse of bridge piers

With the development of science and technology, the finite element method has provided effective analysis methods for many scholars to study the anti-rolling stone collision of bridge pier structures. To convenient for numerical analysis methods reasonably analyzed the dynamic response of bridge pier structures under rolling stone collision, many scholars have conducted many studies involving the calculation method of describing the impact force of a rolling stone, the performance of bridge piers under the impact, and the mechanism of the impact damage of the bridge piers. Many achievements were proposed as follows: a simple motion rule of rolling stones [3], the change law of recovery coefficient of rolling stones [4] and the law of the rolling stone impact force vary with height [5], the dynamic characteristics of bridge piers under the impact [6], and the damage mechanism [7]. These achievements are useful for study of the collision between the rolling stone and the bridge pier. However, some problems beard in the aforementioned studies as follows: Relatively few studies on the dynamic response of bridge pier based on the collision of a rolling stone are available. The exploration of the problem of rolling stone colliding bridge piers is limited, and the antirolling stone collision design of bridge piers is blind. Moreover, conducting multiple sets of experiments under different working conditions is necessary in the experiment of a rolling stone impact to maintain consistency of impact of the rolling stone with the actual situation. However, large experimental engineering will result in some problems as follows: high experimental cost, long experimental period, and difficult data processing.
Based on the above analysis, this study combined the Chang Ba Bridge of Nan Chuan District located at Chongqing of China as the specific research object and used the display dynamics analysis software ANSYS/LS -DYNA to simulate the collision process of a double-column pier collided by rolling stones. This simulation aims to determine the most effective measures to improve the anti-rolling stone collision performance of bridge piers and ameliorate the destruction level of bridge piers by rolling stones.

\section{State of the art}

As a complex and non-linear dynamic response process, the study of the rolling stone collision of bridge piers is still insufficiently discussed. At present, domestic and foreign scholars have developed extensive studies on rolling stone impact and performance of bridge pier under the impact of rolling stones. Some conclusions suitable for engineering design and practice are provided. However, these studies are mainly concentrated in rock fall impact, ship-bridge collision, and vehicle-pier collision. For example, Zhang studied the theoretical model of the maximum impact force of the rolling stones based on the theory of rigid-body motion, and the sliding model of rolling stones with different forms was established. The practicality of the sliding model was then explained by examples, and the sensitivity of some influence parameters was analyzed. Their results showed that the maximum impact force of the rolling stones increased with the impact velocity, angle, and slope under the condition of energy ratio change[8]. Shen studied the impact mechanism of rolling stones on the concrete and the buffer layer above the rock shed via numerical simulation of the discrete element method. The dynamic effect between rock mass and buffer layer was studied by the discrete element model, including impact force, penetration depth, and base force. The results showed that the maximum impact force on the rock mass increased with the sphere velocity, and the corresponding penetration depth linearly decreased [9]. Mavrouli used finite element software to evaluate the mechanical properties of masonry structures under the impact of rolling stones. The main variables affecting the damage degree of masonry structures were identified by analyzing the effect of rolling stone impact on masonry structure. The results showed that the width of the masonry structure, tensile strength, diameter of the rolling stones, and impact velocity of the rolling stones affect the damage degree of the masonry structures [10]. Gao conducted an experimental study on the impact of the rolling stones on the enclosed structure. The impact force of a group of rolling stones moving along the rough slope on the wall of the enclosure structure was measured by a small experiment. The effect of the slope inclination and the position of enclosure structure wall on the impact force of the rolling stones were analyzed. A discrete 3D element model was also proposed. The model was verified by comparing the influence of different materials and geometric parameters on the impact force of the rolling stones. The verification results showed that the different angles of slopes, the regularity of the slope, and the shape of the rolling stones would affect the impact force of the rolling stones [11]. Anna numerically simulated the process of rolling stones impacted on the silt pile used as cushions above the underground openings and verified the results using a large amount of experimental data. The results showed that the 
size of the rolling stones, the impact velocity of the rolling stones, and the thickness of the cushion can influence the impact force of rolling stones [12]. The performance of the old tire cushion under the impact of rolling stones was studied by Sun. The old tire cushion was used to build the model of the reinforced concrete structure, and 12 groups of rolling stone experiments were artificialy conducted according to different qualities and heights of rolling stones and various materials of tires. A simplified calculation model of the spring damper was established by the experiment of radial repetitive compression on the old tires to improve the calculation efficiency. The results showed that the old tire can effectively buffer the maximum impact force of the rolling stones. In the case of the same impact energy, the destructive force of the light mass rolling stone on the tire cushion was larger than that of the heavy mass rolling stone on the tire cushion [13]. Zhao proposed a new cushion layer containing sand and Pearl cotton (EPE) or Expanded Polystyrene (EPS) to relieve the impact of rolling stones on the rock sheds. He also conducted uniaxial compression experiments of the new cushion layer and compared the compressive property of EPS and EPE. Finally, the rolling stone impact tests of the sand, sand-EPS, and sand-EPE on the reinforced concrete boxes were conducted. The results showed that the sand-EPE was the best cushion layer of anti-rolling stone impact[14]. In the above studies on the impact of the rolling stones, the influences of the impact force of the rolling stones on the structure are the research emphasis of these studies. The working performance of the structure under the impact of different rolling stones and the performance of cushioning the impact of the rolling stones are analyzed. These studies on the performance of the structures under the impact of the rolling stones and the influences of the rolling stones on the structures do not start from the dynamic characteristics of the structural system to discuss and relatively few studies on the dynamic response of the rolling stone impact on the bridge pier structures are available. The impact process of the rolling stones on the structures includes plastic deformation and energy dissipation In addition to the impact of the rolling stones, the dynamic characteristics of the structures under the impact of the rolling stones are also an important factor that affects the performance of anti-rolling stone of the structures. The dynamic characteristics of the structures under the impact of the rolling stones must be understood to comprehend the performance of the structure under the impact of the rolling stones. The mutual influence of the collision process between the rolling stones and the structures should also be studied.

Bridge pier collision is a non-linear and complex dynamic response process. Many scholars have investigated the failure mode and dynamic response of the bridge piers under impact to examine their dynamic characteristics comprehensively. For example, Sha established a detailed numerical model of ship-bridge collision by the finite element analysis software and used the rigid, elastic, and nonlinear material models to study the influence of materials on impact force and the crushing depth of ships. The results showed that the response of nonlinear bridge piers and the damage had a significant influence on the collision response of ship-bridge during the process of collision [15]. Gholipour used LS - DYNA software to establish models of the bridge piers with different structural and geometric features and numerically simulated the collision process between the ships and the bridge piers. The effects of energy distribution during the collision process between the ships and the bridge piers were analyzed by comparing the result of energy distribution between the two. The results showed that the internal force contribution of the ships was larger than that of the members of the bridge piers during collision of the ships with the rigid bridge piers. The bridge piers had more internal force contribution when the ships collide with other types of bridge piers [16]. Gholipour conducted a dropping shock test on reinforced concrete columns under the effect of axial load and compared the failure mode and impact responses of the reinforced concrete columns. The test results showed that the reduction of the impact elevation caused the increase in initial peak impact. The increase in the initial peak impact force changed the failure mode of the columns from the integral-deflection mode to the sheardeflection total shear failure mode; the increase in the axial load ratio raised the initial peak impact force [17]. Pan designed a new type of energy-saving device filled with Ushaped thin-wall steel sheet and Fiber Reinforced Polymer (FRP) and conducted the horizontal impact test. The test results showed that the protective structure of the bridge piers designed with thin-wall steel sheet and FRP had good performance of anti-rolling stone impact [18].

The above studies on collision of bridge piers mainly concentrated in the failure mode of bridge piers during ship-bridge and vehicle-bridge collisions and the collision model between the bridge piers and the ships or vehicles. However, relatively few studies on the dynamic response of bridge piers based on the rolling stone collision are available. At present, domestic and foreign scholars have conducted numerous studies on the dynamic response of structures under impact. For example, He used nonlinear finite element analysis method to simulate the impact process of the rolling stones on the bridge piers numerically and developed a new type of anti-impact damping device for bridge piers. The research results showed that the impact force of the protective structures was reduced by $30 \%$ when the bridge piers were under the impact loading, and the shock resistance of the bridge piers was significantly improved. The device could protect the bridge pier, but the performance of the device required additional accurate and complete tests for verification and optimization [19]. Liu studied the dynamic responses of reinforced concrete piers under impact loads of mass by using the finite element analysis software ANSYS/LS - DYNA. A common node separate model was adapted to the dynamic responses. The results indicated that vibration frequency at the top of pier column along the transverse direction was more than that in the impacted position under the action of impact[20]. Anbuvelan studied the impact resistance of fibrous concrete by using ACI drop weight Impact tester. Two grades of concrete's namely $\mathrm{Ml}$ and $\mathrm{M} 2$ were considered in this investigation with $0.5,1.0,1.5$ and $2.0 \%$ dosage of steel fiber. The experimental test results of steel reinforced fiber concrete were compared with plain concrete and conclusions were arrived [21]. Xiao performed the numerical simulation of the rolling stones impacting on the bridge piers. The simulation results showed that the initial impact kinetic energy of the rolling stones and the form and concrete strength grade of the bridge piers would affect the dynamic response of the bridge piers [22]. Guo considered the influence of pile-soil interaction and superstructure constraint on the dynamic response of the rolling stone impact on the bridge piers and studied the damage of the bridge piers impacted by the rolling stones. The results 
showed that the displacement response, steel stress, and damage index of the double-column bridge piers were considerably larger than those of the independent piers [23]. However, the problem of rolling stone collision with bridge piers may not have been exhaustively studied. Moreover, the double-column bridge piers with the coupling beam are rarely considered. The conclusion of the above studies cannot accurately reflect the true dynamic response of the double-column bridge piers with coupling beam under the impact of the rolling stones.

Therefore, considering the shortcomings of the existing studies, a simulation analysis of dynamic response on double-column bridge piers based on the collision of a rolling stone was conducted in this study. This study took the Chang Ba Bridge of Nan Chuan District located at Chongqing of China as a specific research object prototype, and simulates the process of the rolling stones impacting on the double-column bridge piers through the display dynamics analysis software ANSYS/LS - DYNA. The stress time-history and the displacement curves of the key parts are analyzed to summarize the dynamic response of the doublecolumn bridge piers under the impacts of the rolling stones with different initial velocities and impact positions.

The remainder of this study is organized as follows. Section 3 describes the determination of the parameters of the finite element models. Section 4 presents the stress time history and key part displacement curves and analyzes the results. Section 5 summarizes the conclusions.

\section{Methodology}

\subsection{Engineering background}

The specific research object of this study is the Chang $\mathrm{Ba}$ Bridge of Nan Chuan District located at Chongqing of China. The bridge pier is located on the slope. The influence of wind was considered when the bridge was calculated, but the influence of the earthquake force, the pressure of water flow, and the impact force of the floater was disregarded. The large volume of the bridge pier and its large excavation volume easily lead to landslide, collapse, and other geological hazards. These disasters result in rolling stone impact on the bridge piers. The rolling stones are granite and spherical. The form of the bridge pier is a double-column bridge pier. The height of the bridge pier is $40 \mathrm{~m}$, and the radius of the cross-section of the bridge pier is $1.15 \mathrm{~m}$. The concrete cover thickness and strength grade of the bridge pier are $5 \mathrm{~cm}$ and C50, respectively. The bridge pier has 48 pieces of longitudinal reinforcements, and the diameter of the bridge pier is $12 \mathrm{~mm}$. The diameter of the stirrup of the bridge pier is $12 \mathrm{~mm}$. The strength of the reinforcements are HRB335, and the spacing of the stirrup is $200 \mathrm{~mm}$. The basic parameters of the bridge pier are shown in Table. 1 .

Table 1. Basic parameters of the bridge pier

\begin{tabular}{c|c|c|c|c|c}
\hline $\begin{array}{c}\text { Pier } \\
\text { height }\end{array}$ & $\begin{array}{c}\text { Pier } \\
\text { diameter }\end{array}$ & $\begin{array}{c}\text { Coupling } \\
\text { beam } \\
\text { thickness }\end{array}$ & $\begin{array}{c}\text { Longitudinal } \\
\text { reinforcement's s } \\
\text { pieces }\end{array}$ & $\begin{array}{c}\text { Reinforcement } \\
\text { ratio (\%) }\end{array}$ & $\begin{array}{c}\text { Stirrup } \\
\text { ratio } \\
\text { (\%) }\end{array}$ \\
\hline $40 \mathrm{~m}$ & $1.15 \mathrm{~m}$ & $2.2 \mathrm{~m}$ & 48 & $0.92 \%$ & $0.11 \%$ \\
\hline
\end{tabular}

\subsection{Finite element modeling}

This study defines the rolling stones as a rigid body to save the calculation time because the stress variation of the rolling stone need not be considered during the process of rolling stone impact on the bridge pier. The initial spacing between the rolling stone and the bridge pier is $100 \mathrm{~mm}$. The simulation is conducted by the software ANSYS/LS DYNA. The calculation time is an automatic time step. The calculation time duration of $1 \mathrm{~s}$ is observed to determine the dynamic response of the bridge pier under the impact of the rolling stone. The finite element models of the bridge pier, rolling stone, longitudinal reinforcement, stirrup, and mesh reinforcement are shown in Fig. 2 to Fig. 6.

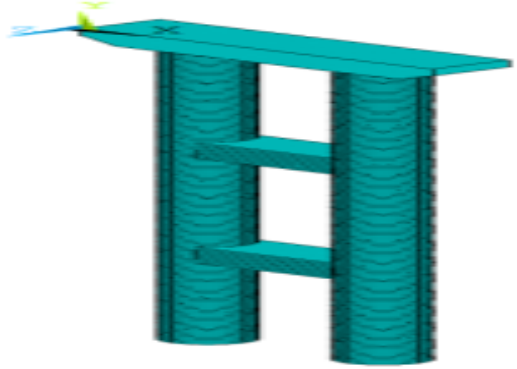

Fig. 2. Finite element model of the bridge pier

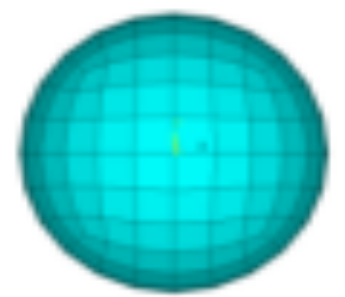

Fig. 3. Finite element mode of the rolling stone

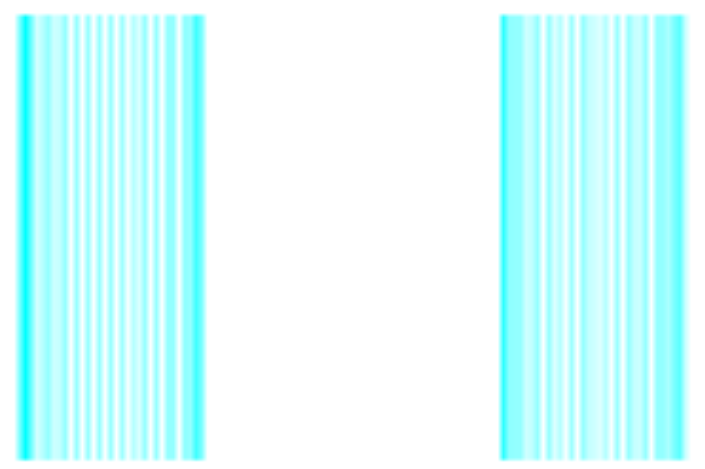

Fig. 4. Finite element mode of the longitudinal reinforcement

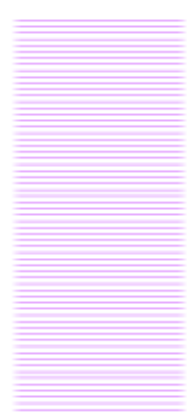

Fig. 5. Finite element model of the stirrup

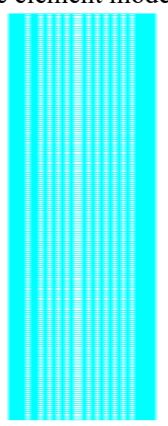

Fig. 6. Finite element model of the mesh reinforcement 
The Holmquist - Johnson- - Cook (HJC) constitutive model is adopted for the concrete material during the numerical analysis. The material parameters of the HJC model of the concrete material refer to numerous references [24]. The material parameters of the HJC constitutive model adopted in the simulation of this study are shown in Table 2. Among these parameters, the density of concrete is taken as $\rho=2500 \mathrm{~kg} \cdot \mathrm{m}^{-3}$. The hydrostatic compressive strength of C50 concrete is taken as $f_{c}^{\prime}=48 M P a$, which is derived from $P_{c}=16$. The elastic modulus of concrete is taken as $3.45 \mathrm{GPa}$. Poisson ratio is taken as $v=0.2$ for highstrength concrete. Therefore, the shear elastic modulus G, the bulk modulus $K_{e}$, and the volumetric strain $\mu_{c}$ of the concrete during the linear elastic stage can be obtained, and the calculation formula is shown in formulas (1) to (3):

$$
G=\frac{E}{2(1+v)}
$$

$$
K_{e}=\frac{E}{3(1-2 v)}
$$

$\mu_{c}=\frac{P_{c}}{K_{e}}$

The conclusion can be calculated by these formulas: $\mathrm{G}=$ $14.4 \mathrm{GPa}, K_{e}=1.74$ and $\mu_{c}=9.2$. These values are taken according to the reference [25] in this study because of the change of the strength parameters $\mathrm{A}, \mathrm{B}, \mathrm{N}$, and $\mathrm{C}$ of the material in the simulation have little effect on the shape of the stress-strain curve. The parameters of the HJC constitutive model of concrete used in the simulation are shown in Table. 2. The material constitutive of the reinforced adopts servo enhanced bilinear elastic plastic model, and the parameters of this model are shown in Table. 3. Adopting the rigid body model can save a considerable amount of calculation time. Simultaneously, the failure form of the rolling stone is ignored during the impacting of the rolling stone on the bridge pier. Moreover, the calculation will be accurate if the rolling stone is regarded as a rigid body and the deformation of the impacting process is disregarded. The material parameters are shown in Table. 4.

Table 2. Material parameters of concrete HJC constitutive model

\begin{tabular}{c|c|c|c}
$\rho / 10^{3} \mathrm{~kg} \cdot \mathrm{m}^{-3}$ & $\mathrm{c}$ & $K_{1} / \mathrm{MPa}$ & $\mathrm{A}$ \\
2.5 & 0.007 & 85 & 0.79 \\
$G / \mathrm{MPa}$ & $\mathrm{N}$ & $K_{2} / \mathrm{MPa}$ & $D_{1}$ \\
14.4 & 0.61 & -171 & 0.04 \\
$T / M P a$ & $\varepsilon_{f \min }$ & $K_{3} / M P a$ & $S_{\max }$ \\
0.4 & 0.01 & 208 & 7.0 \\
$P_{\text {crush }} / \mathrm{MPa}$ & $f_{c}^{\prime}$ & $\mu_{\text {crush }}$ & $\mu_{\text {lock }}$ \\
16 & 48 & $0.833 E^{-3}$ & 0.1 \\
$P_{\text {lock }} / G p a$ & $\dot{\varepsilon}$ & $D_{2}$ & $\mathrm{~B}$ \\
0.8 & 1 & 1 & 1.60 \\
\hline
\end{tabular}

Table 3. Constitutive model parameters of steel materials

\begin{tabular}{c|c|c|c|c}
\hline$\rho / 10^{3} \mathrm{~kg} \cdot \mathrm{m}^{-3}$ & $E / G p a$ & $v$ & $\sigma_{0} / M P a$ & $E_{t} / G p a$ \\
\hline 7.8 & 200 & 0.3 & 335 & 1.2
\end{tabular}

\begin{tabular}{c|c|c}
$C / S^{-1}$ & $\mathrm{P}$ & $f$ \\
40 & 5 & 0.2
\end{tabular}

Table 4. Constitutive model parameters of rolling stone materials

\begin{tabular}{c|c|c}
\hline$\rho / 10^{3} \mathrm{~kg} \cdot \mathrm{m}^{-3}$ & $E_{s} / \mathrm{Gpa}$ & $v$ \\
\hline 2.3 & 2.63 & 0.22 \\
\hline
\end{tabular}

\subsection{Model conditions}

The influence of the bridge height and the depth of the pile foundation and soil on the impact response of the bridge wasn't studied. The height of the bridge pier is $\mathrm{H}=40 \mathrm{~m}$, and the restriction effect of the bottom of the bridge pier is replaced by consolidation. This study conducted modeling analysis according to different conditions of the initial velocity of the rolling stone and the impact position. The bridge pier, steel bar, and rolling stone are respectively simulated by solid164, link160, and solid164 units. The parameters of different impact velocities and positions of the rolling stone are shown in Table. 5.

Table 5. Parameters of different conditions

\begin{tabular}{c|c|c|c|c}
\hline Condition & $\begin{array}{c}\text { Rolling stone's } \\
\text { impact velocity } \\
(\mathbf{m} / \mathbf{s})\end{array}$ & $\begin{array}{c}\text { Impact } \\
\text { position }\end{array}$ & $\begin{array}{c}\text { Rolling stone's } \\
\text { radius }\end{array}$ & $\begin{array}{c}\text { Form of the } \\
\text { bridge pier }\end{array}$ \\
\hline 1 & 3 & $\mathrm{H} / 3$ & 0.68 & \\
2 & 5 & $\mathrm{H} / 3$ & 0.68 & Double- \\
3 & 10 & $\mathrm{H} / 3$ & 0.68 & column \\
4 & 3 & $\mathrm{H} / 2$ & 0.68 & bridge \\
5 & 5 & $\mathrm{H} / 2$ & 0.68 & pier \\
6 & 10 & $\mathrm{H} / 2$ & 0.68 & \\
\hline
\end{tabular}

\section{Result Analysis and Discussion}

4.1 Comparative analysis of the dynamic response of the bridge pier under conditions $1-3$

The dynamic response of the double-column bridge pier to the impact of the rolling stone under conditions of 1-3 is discussed. The impact velocities of the rolling stone are 3,5 , and $10 \mathrm{~m} / \mathrm{s}$, and the distance from the impact position to the top of the bridge pier is $\mathrm{H} / 3$. The radius of the rolling stone is $0.68 \mathrm{~m}$.

\subsubsection{Stress time-history analysis on bridge pier during impact process}

The equivalent stress diagram of the impact region of the double-column bridge pier with time is shown in Fig. 7. The analysis results show that the maximum stress of the doublecolumn bridge pier is in the impacted region at the moment when the double-column bridge pier is impacted by the rolling stone, and considerable stress occurred in the binding site of the bridge pier and the coupling beam (Fig. 8).

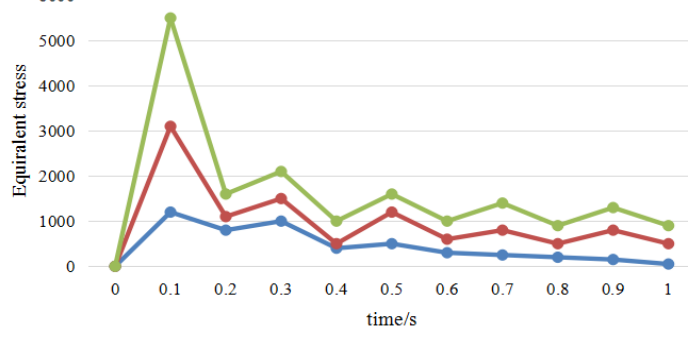

Fig. 7. Dynamic time history diagram of the bridge pie under conditions $1-3$ 


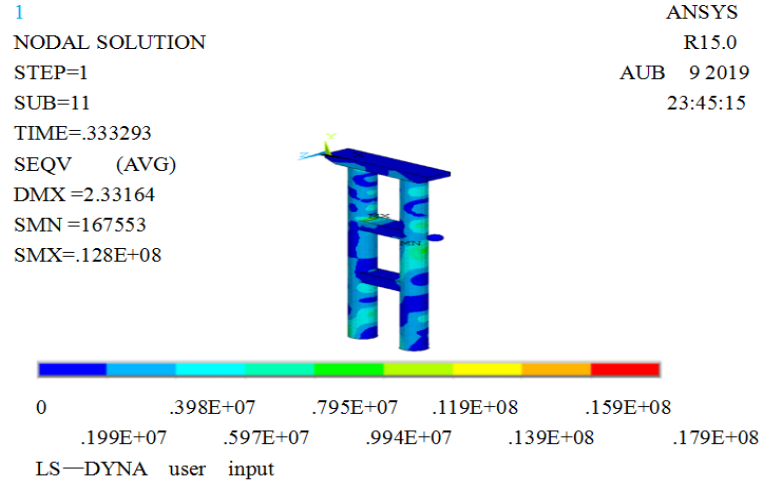

Fig. 8. Overview of stress distribution of bridge pier

Under condition 1 , the equivalent stress value of the impacting part reached the first stress maximum of $130 \mathrm{MPa}$ at $\mathrm{t}=0.1 \mathrm{~s}$, rapidly decreased, and then reached the new second stress maximum of $60 \mathrm{MPa}$. The stress maximum that subsequently occurred was not as large as the first stress maximum. Under condition 2, the equivalent stress value of the impacting part reached the first stress maximum of $300 \mathrm{MPa}$ at $\mathrm{t}=0.1 \mathrm{~ms}$, rapidly decreased, and then reached the new second stress maximum of $100 \mathrm{MPa}$. The stress maximum that subsequently occurred was not as large as the first stress maximum. Under condition 3, the equivalent stress value of the impact reached the first stress maximum of $550 \mathrm{MPa}$ at $\mathrm{t}=0.1 \mathrm{~s}$, rapidly decreased, and then reached a new second stress maximum of $150 \mathrm{MPa}$. Then, the stress maximum rapidly decreased again and reached a new stress maximum. The stress maximum that subsequently appeared was not as large as the first stress maximum.

The results presented in Fig. 7 are analyzed. Under conditions $1-3$, the variation of the equivalent stress of the bridge pier demonstrates the following: condition $3>$ condition $2>$ condition 1 . A large impact initial velocity of the rolling stone results in a large change in the equivalent stress of the bridge pier. From the perspective of energy conversion, a large impact initial velocity of the rolling stone leads to a large kinetic and transferred energy to the bridge pier at the moment of impact. After the rolling stone left the impacted surface of the bridge pier, no kinetic energy of the rolling stone transfer to the bridge pier, and the impacted area of the bridge pier is diffused to other positions due to the distribution of energy. Therefore, the stress maximum that subsequently occurred is not as large as the first. In addition, a section break is observed in the area where the coupling beam and the bridge pier were connected. Therefore, concentration of stress possibly occurs during energy diffusion in the impacted area of the bridge pier. Except where the area is hit, the stress change of the connecting part of the coupling beam and the bridge pier is more prominent compared with that of the other areas.

\subsubsection{Time-history analysis on the displacement of key parts of the bridge pier during impact process}

The nodal displacement of the double-column bridge pier can reflect the local displacement deformation of the doublecolumn bridge pier after the impact of the rolling stone. The time-history curve of the key nodes of the impacted part of the double-column bridge pier is shown in Fig. 9, and the displacement time-history diagram of the key node of the impacted part of the double-column bridge pier is analyzed.

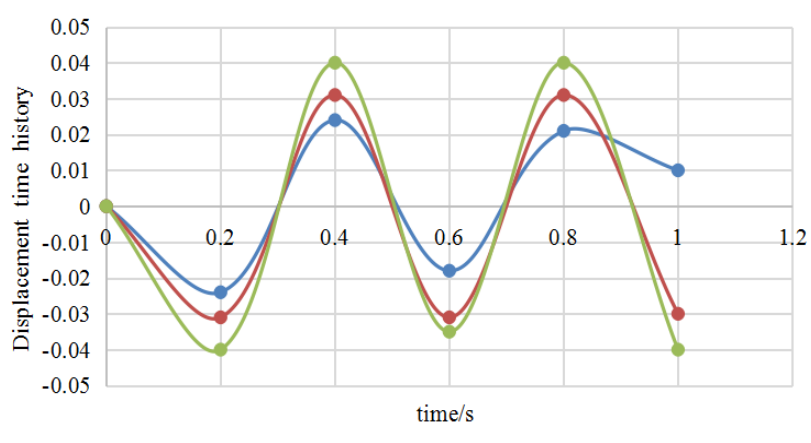

$\longrightarrow-$ condition $1 \multimap$ condition $2 \multimap$ condition 3
Fig. 9. Displacement time history of key parts under conditions $1-3$

From the analysis of the key node displacement diagram, the displacement of the key node of the impact part rapidly increased at the moment of impact under condition 1 . The displacement then decreased until the reverse displacement reached the maximum value of $2.41 \mathrm{~mm}$ and increased toward the impact direction. At $\mathrm{t}=0.4 \mathrm{~s}$, the displacement reached the maximum value of $2.41 \mathrm{~mm}$ and then exhibited an oscillating change tendency. Under condition 2, the displacement of the key node of the impacting part rapidly increased at the moment of impact and then decreased until the reverse displacement reached the maximum value of 3.2 $\mathrm{mm}$. Then, the displacement increased toward the impact direction. At $\mathrm{t}=0.4 \mathrm{~s}$, the displacement reached the maximum value of $3.2 \mathrm{~mm}$ and then exhibited an oscillating change tendency. Under condition 3, the displacement of the key node of the impact part rapidly increased at the moment of impact and then decreased until the reverse displacement reached a maximum value of $4 \mathrm{~mm}$. The displacement then increased toward the impact direction and reached a maximum value of $4 \mathrm{~mm}$ at $\mathrm{t}=0.4 \mathrm{~s}$. Afterward, this displacement exhibited an oscillating change tendency.

The results shown in Fig. 9 are analyzed. Under conditions $1,2-3$, the displacement changes of the key parts is as follows: condition $3>$ condition $2>$ condition 1 . This finding indicates that the larger the impact initial velocity of the rolling stone is, the more severe the change of the displacement of the key part of the bridge pier. Moreover, the absolute value of the displacement change of the impact and the counter-impact directions is almost equal in the case of neglecting the secondary factor.

\subsection{Analysis on Dynamic Response of the Bridge Pier under Conditions 4 - 6}

The dynamic response of the double-column bridge pier to the impact of the rolling stone under conditions 4-6 is discussed. The impact velocity of the rolling stone is 3,5 , and $10 \mathrm{~m} / \mathrm{s}$, and the distance from the impact position to the top of the bridge pier is $\mathrm{H} / 2$. The radius of the rolling stone is $0.68 \mathrm{~m}$.

\subsubsection{Stress time-history analysis on bridge piers during impact process}

The equivalent stress diagram of the impact region of the double-column bridge pier with time is shown in Fig. 10. The analysis results show that under condition 4, the maximum stress of the double-column bridge pier structure appeared in the impacted area. The bottom of the bridge pier and the connecting part between the bridge pier and the 
coupling beam demonstrated considerable stress. At $\mathrm{t}=0.1 \mathrm{~s}$, the equivalent stress value of the impact part reached the first stress maximum of $140 \mathrm{MPa}$, rapidly decreased, and then reached the new second stress maximum of $100 \mathrm{MPa}$. The subsequent occurrence of stress maximum was not as large as the first.

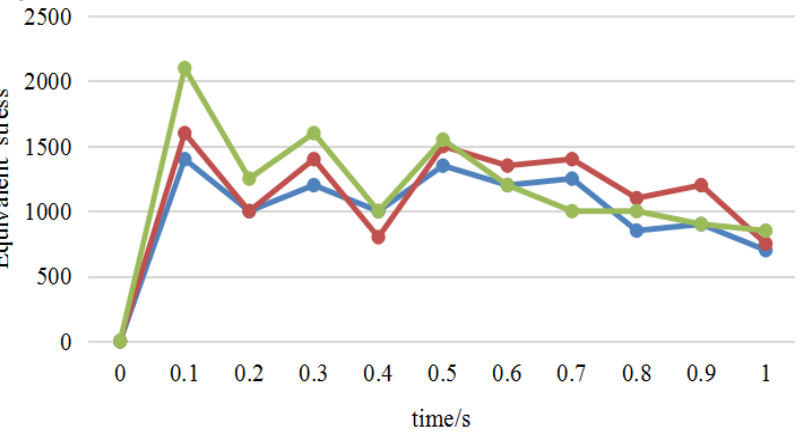

$\longrightarrow$ condition $4 \longrightarrow$ condition $5 \multimap$ condition 6

Fig. 10. Dynamic time-history diagram of piers $4-6$

Fig. 7 and Fig. 10 show that the stress of the bridge pier would vary with different impact positions. The stress change under the $\mathrm{H} / 3$ from the bottom of the upper structure of the bridge pier was more than that in the case of $\mathrm{H} / 2$. When the impact position is close to the bottom of the bridge pier, the energy of the rolling stone into the bridge pier was rapidly distributed to the bottom. The pile foundation was introduced into the ground and absorbed part of the energy. Therefore, under conditions 4-6, the stress of the bridge pier was affected by the different impact positions. The stress maximum of the bridge pier under conditions 4-6 was smaller than that of the bridge pier under conditions $1-3$.

4.2.2 Time-history analysis on the displacement of key parts of the bridge pier during impact process

The nodal displacement of the double-column bridge pier can reflect the local displacement deformation of the doublecolumn bridge pier after the impact of the rolling stone. The time-history curve of the key nodes of the impacted part of the double-column bridge pier is shown in Fig. 11, and the displacement time-history diagram of the key node of the impacted part of the double-column bridge pier is analyzed.

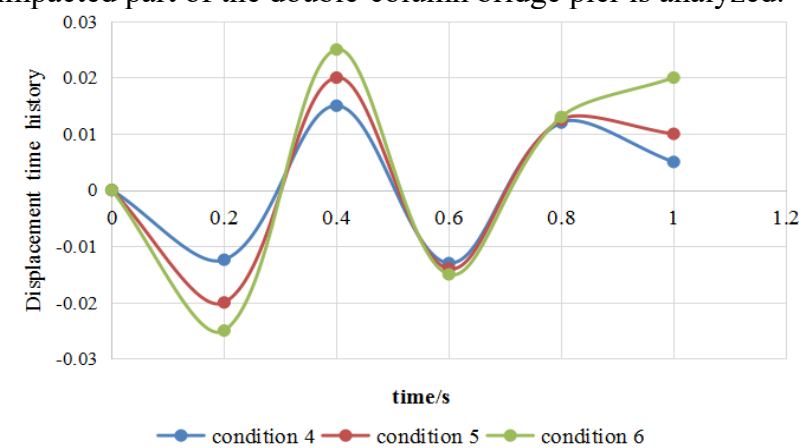

Fig. 11. Displacement diagram of key nodes in the impact area of the bridge pier

The analysis of the key node displacement diagram shows that under condition 4 , the displacement of the key node of the impact part rapidly increased at the moment of impact. Afterward, the displacement decreased until the reverse displacement reached the maximum value of $1.3 \mathrm{~mm}$ and then increased toward the impact direction. At $\mathrm{t}=0.4 \mathrm{~s}$, the displacement reached the maximum value of $1.3 \mathrm{~mm}$ and then exhibited an oscillating change tendency.
The results in Fig. 9 and Fig. 10 indicate that the closer the impact position was to the bottom of the bridge pier due to the restraining action of the bottom, the greater influence of the bottom constraint on the displacement of the key points of the bridge pier.

\subsection{Stress time-history analysis of steel bar}

\subsubsection{Stress time-history analysis of longitudinal reinforcement}

The stress time-history diagram of the longitudinal reinforcement of the bridge pier at the impact moment of the rolling stone to the bridge pier under condition 1 is shown in Fig. 12.

The stress time-history diagram of the longitudinal reinforcement of the bridge pier indicates the appearance of the maximum stress (34.5 $\mathrm{MPa})$ of the longitudinal reinforcement at the bottom of the bridge pier. The longitudinal reinforcement didn't reach the yield strength of the steel bar and the longitudinal reinforcement and the concrete could still participate in the force with bridge pier concrete. Under conditions $2-6$, the stress time-history of the longitudinal reinforcement of the bridge pier was the same and the yield strength of the steel bar was not reached.

\subsubsection{Stress time-history analysis of stirrups}

The stress time-history diagram of the stirrups at the impact moment of the rolling stone to the under condition 1 is shown in Fig. 13.

The stress time-history diagram of the stirrups of the bridge pier reveals the appearance of the maximum stress (34.5 MPa) of the stirrups at the bottom of the bridge pier. The stirrups did not reach the yield strength of the steel bar and his stirrups and the concrete could still participate in the force with the bridge pier concrete. Under conditions 2-6, the stress time-history of the stirrups of the bridge pier was the same and the yield strength of the steel bar was not reached.

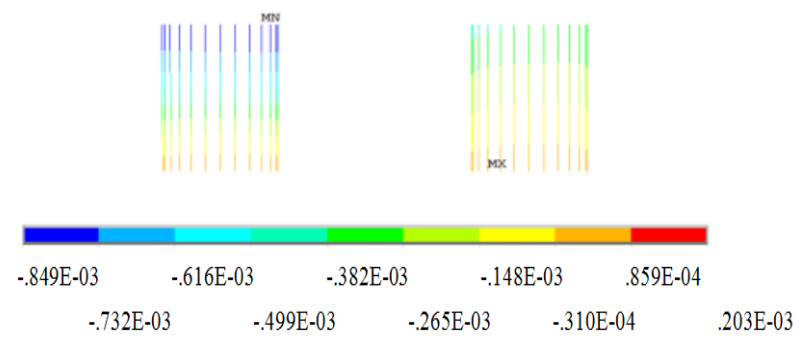

Fig. 12. Stress time-history diagram of longitudinal reinforcement of bridge pier

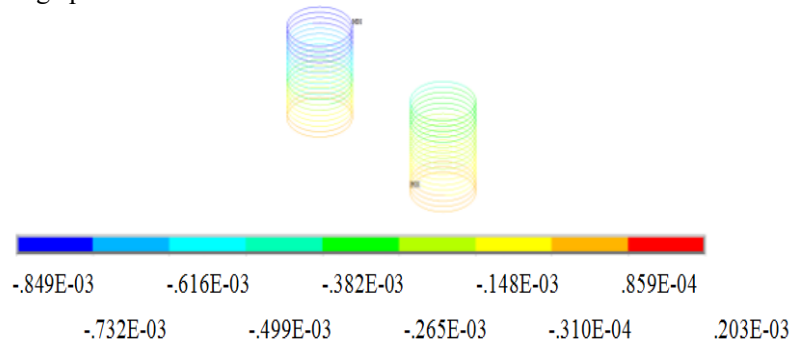

Fig. 13. Stress time-diagram of stirrups of bridge pier

\section{Conclusions}

The stress variation of the bridge pier under the impact of the rolling stone and that of the displacement of the key 
parts of the bridge pier were analyzed in this study by using the finite element simulation. This simulation was conducted to improve the anti-rolling stone collision performance of bridge piers and reduce its damage due to the collision of rolling stones. The dynamic response of the bridge pier under the impact of the rolling stone with varying impact positions and initial velocities was comparatively analyzed. On this basis, the contributing factors of dynamic response variation of the bridge pier were analyzed. The following conclusions could be drawn.

(1) Stress change of the impacted position of the bridge pier is related to the initial velocity of the rolling stones. The maximum value of stress change of the bridge pier increases with the initial velocity of the rolling stone.

(2) After being impacted by rolling stone, the damaged area of the bridge pier is mainly concentrated in the impacted area.

(3) Except for the impacted area, the connecting part between the bridge pier and the coupling beam is also the vulnerable area after rolling stone impact.

(4) Restriction effect at the bottom of the bridge pier affects the dynamic response of the bridge pier under the impact of the rolling stone, and the influence degree increases with the reduction in the distance from the impacting position to the bottom of the bridge pier.

(5) The results from this study indicate that the influence of the rolling stone impact on the bridge pier was small when the impact velocity of the rolling stone did not exceed $10 \mathrm{~m} / \mathrm{s}$. The dynamic response of the bridge pier mainly concentrated on the stress and displacement changes of the key parts. The maximum stresses of the longitudinal reinforcement and the stirrup of the bridge pier appeared at the bottom of the bridge pier and did not exceed $35 \mathrm{MPa}$.
The longitudinal reinforcement and the stirrup still maintained the normal use function.

Overall, the simulation on the double-column bridge pier of mountain bridges in this study is easy to operate and can effectively observe the stress changes in bridge piers and steel bars. These findings lay the foundation for further analyzing dynamic responses of impacted bridge piers under complicated conditions. However, certain deviations between the set model parameters and the actual ones may be observed because the effects of the pile foundation on the bridge pier were disregarded in this study and the bottom constraint of the bridge pier was simplified. Thus, recommending the influences of the factors (such as bottom restraint, pile foundation depth, and pile foundation form) on the dynamic response of the bridge pier to enrich working conditions will provide guidance in the further study of the dynamic response of double-column bridge piers of mountain bridges under the impact of rolling stones.

\section{Acknowledgements}

The authors are grateful for the support provided by the key Laboratory of Water Conservancy and Waterway Engineering, Ministry of Education, Open Fund Project (SLK2017B03), Chongqing Foundation and Frontier Research Projects Foundation (cstc2017jcyjAX0189); Chongqing Municipal Education Commission Science and Technology Research Project (KJ1801339) and Chongqing Science and Technology Institutions Fund Project (CK2016B09).

This is an Open Access article distributed under the terms of the Creative Commons Attribution License

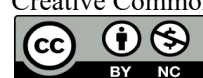

\section{References}

1. Lam, C., Yong, A. C. Y., Kwan, J. S. H., "'Overturning stability of L-shaped rigid barriers subjected to rockfall impacts', Landslides, 15(7), 2018, pp.1347-1357.

2. Luo, Z., Wang, Y. H., "Experiment on Dynamic Response of Piers Subjected to Rolling Stone Impacting',.China Journal of Highway Transport, 30(09), 2017, pp.78-85.

3. Biagi, V. D., Napoli, M. L., Barbero, M., “A quantitative approach for the evaluation of rockfall risk on buildings"'. Natural Hazards, 88(2), 2017, pp.1059-1086

4. Chau, K., Wong, R., Wu, J., "'Coefficient of restitution and rotational motions of rockfall impacts".International Journal of Rock Mechanics and Mining Sciences, 39(1), 2002, pp.69-77.

5. Lorentz, J., "Experimental study of the dissipative efficiency of a multilayered protective structure against rock fall impact',. Revue Européenne De Génie Civil,10(3),2006,pp.295-308.

6. Joshi, A. S., Gupta, L. M., "A simulation study on quantifying damage in bridge piers subjected to vehicle collisions", International Journal of Advanced Structural Engineering, 4(1), 2012, pp.8.

7. Wang, W., Morgenthal, G., “Dynamic analyses of square RC pier column subjected to barge impact using efficient models". Engineering Structures, 151, 2017, pp.20-32.

8. Zhang, S. L., Yang, X. G., Zhou, J. W., "A theoretical model for the estimation of maximum impact force from a rockfall based on contact theory'.Journal of Mountain Science, 015(02), 2018, pp.430-443.

9. Shen, W. G., Zhao, T., Dai, F., Jiang, M. J., “DEM analyses of rock block shape effect on the response of rockfall impact against a soil buffering layer'. Engineering Geology, 249, 2018, pp.60-70.

10. Mavrouli, O., Giannopoulos, P. G., Carbonell, J. M., Syrmakezis, C., "Damage analysis of masonry structures subjected to rockfalls". Landslides, 14(3), 2017, pp.891-904.
11. Gao, G., Meguid, M. A., "Modeling the Impact of a Falling Rock Cluster on Rigid Structures". International Journal of Geomechanics, 18(2), 2018, pp.04017141.

12. Anna, E., Anna, G., "Numerical Investigation of Rockfall Impacts on Muck piles for Underground Portals". Rock Mechanics and Rock Engineering, 50(6), 2017, pp.1569-1583.

13. Sun, J. H., Chu, Z. J., Liu, Y. F., Luo, W. M., Wang, M., "Performance of Used Tire Cushion Layer under Rockfall Impact", Shock and Vibration, 2016, pp: 1-10.

14. Zhao, P., Xie, L. Z., Li, L. P., Liu, Q., Yuan, S., "Large-scale rockfall impact experiments on a RC rock-shed with a newly proposed cushion layer composed of sand and EPE". Engineering Structures, 175, 2018, pp.386-398.

15. Sha, Y. Y., Hao, H., "Nonlinear finite element analysis of barge collision with a single bridge pier'. Engineering Structures, 41(8), 2012, pp.63-76.

16. Gholipour, G., Zhang, C. W., Li, M., "Effects of soil-pile interaction on the response of bridge pier to barge collision using energy distribution method'. Structure and Infrastructure Engineering, 14(11), 2018, pp.1520-1534.

17. Gholipour, G., Zhang, C. W., Mousavi, A. A., "Effects of axial load on nonlinear response of RC columns subjected to lateral impact load: Ship-pier collision'. Engineering Failure Analysis, 91, 2018, pp.397-418.

18. Jin, P., Han, F., Cai, X. M., "'Study on the performance of energy absorption structure of bridge piers against vehicle collision", Thin-Walled Structures, 130, 2018, pp.85-100.

19. He, S. M., Yan, S. X., Deng, X., Liu, W., "Impact protection of bridge piers against rockfall'. Bulletin of Engineering Geology and the Environment, 78(4), 2019, pp.2671-2680. 
Wang Zijian, Zhang Jianing, Hu Jinpeng, Yang Bo, Wu Liming and Piao Lihua./

Journal of Engineering Science and Technology Review 13 (3) (2020) 134 - 142

20. Liu, X., Wang, R. H., Jia, B., "Numerical Analysis on Dynamic Responses of the Reinforced Concrete Piers under Impact Loads of Mass Objects"'. Applied Mechanics and Materials, 501-504, 2014, pp.1348-1351.

21. Anbuvelan, K., "Experimental Studies on Impact Characteristics of Steel Fibre Reinforced Concretes". Research journal of applied science, engineering and technology, 2014, 8(14), pp.1625-1629.

22. Xiao, L. Z.," Research on the impact of mountain rolling stone on the pier and its reinforcement'. Master Thesis of Southwest Jiaotong University, China, 2017,pp.36-66.
23. Guo, Y. K., "Dynamic Response Analysis of Rolling Stones in Mountainous Area Based on Pile-soil Interaction and Superstructure Constraints'. Master thesis of Chang' a University, China, 2018, pp.30-79.

24. Zhang, S. R., Song, R., Wang, C., Shang, C., Wei, P. Y., "Modification of a dynamic constitutive model-HJC model for roller compacted concrete and numerical verification', Journal of Vibration and Shock, 38(12), 2019, pp.25-31.

25. Wu, X. T., Li, Y., Li, H. P., " Research on parameters of constitutive model of concrete HJC '.Chinese Journal of Applied Mechanics, 27(02), 2010, pp.340-344+443. 